\begin{tabular}{l|l|c}
\hline \hline Vol. 26(2):333-339 & Ocean and Polar Research & June 2004 \\
\hline \hline
\end{tabular}

\title{
Article
}

\author{
직교배열표 실험계획법에 의한 심해 연약지반용 무한케도차량의 \\ 견인성능에 대한 실험적 연구 \\ 최종수 $^{*} \cdot$ 홍 섭 $^{1} \cdot$ 김형우 $^{1} \cdot$ 이태희 $^{2}$ \\ 1한국해양연구원 해양개발시스템연구본부 \\ (305-600) 대전광역시 유성우체국 사서함 23호 \\ 2한양대학교 기계공학부 \\ (133-791) 서울시 성동구 행당동 17
}

\section{An Experimental Study about Tractive Performance of Tracked Vehicle on Deep-sea Soft Sediment Based on Design of Experiment Using Orthogonal Array}

\author{
Jong-Su Choi ${ }^{1 *}$, Sup Hong ${ }^{1}$, Hyung-Woo Kim¹, and Tae Hee Lee ${ }^{2}$ \\ ${ }^{1}$ Ocean Development System Laboratory, KORDI \\ Yuseong P.O. Box 23, Daejeon 305-600, Korea \\ ${ }^{2}$ School of Mechanical Engineering, Hanyang University \\ Seoul 133-791, Korea
}

\begin{abstract}
This paper is concerned with an experimental investigation about tractive performance of a tracked vehicle on extremely soft soil. A tracked vehicle model with principal dimensions of $0.9 \mathrm{~m}(\mathrm{~L}) \times$ $0.75 \mathrm{~m}(\mathrm{~B}) \times 0.4 \mathrm{~m}(\mathrm{H})$ and the weight of $167 \mathrm{~kg}$ was constructed with a pair of driving chain links driven by two AC-servo motors. The tracks are configured with detachable grousers with variable span. Deep seabed was simulated by means of bentonite-water mixture in a soil bin of $6.0 \mathrm{~m}(\mathrm{~L}) \times 3.7 \mathrm{~m}(\mathrm{~B}) \times 0.7 \mathrm{~m}(\mathrm{H})$. Slip of vehicle and driving torque of motor were measured with respect to experimental variables; grouser span, grouser chevron angle, driving speed, drawbar-pull weight, position of center-of-gravity and weight. $\mathrm{L}_{8}$ orthogonal array is adopted for DOE (Design Of Experiment). The effects of experiment variables on traction performance are evaluated.
\end{abstract}

Key words : 점착성 지반(cohesive soil), 무한궤도차량(tracked vehicle), 직교배열표(orthogonal arrays), 실 험계획법(Design Of Experiment), 그라우저(grouser), 견인시험(drawbar-pull test), 슬립(slip), 구동토오크 (driving torque)

1. 서 론

본 연구는 심해저 광물자원용 채광시스템의 집광시스템 을 개발하기 위하여 수행되었다. 본 연구에서 고려중인 채

*Corresponding author. E-mail : jschoe@kriso.re.kr
광시스템은 연약 지반위를 이동하면서 광물자원을 모으는 집광시스템과 집광된 단괴를 해상으로 이송시키는 양광시 스템, 해상에서 전체 위치를 이동시키면서 전체를 제어하 는 역할을 하는 해상플랫폼 등으로 구성된다. 집광시스템 은 다시 해저 연약지반상에서 시스템 전체에 견인력을 제 공하는 주행장치와 단괴를 모으는 채집장치 그리고 채집 
된 단괴를 양광시스템으로 이송시키는 송출장치로 구성되 어 있다. 해저 연약지반용 주행장치의 기본 설계자료와 개 발 중에 있는 주행장치 전산모델의 검증자료를 언기 위하 여 본 연구가 수행되었다.

망간단괴와 같은 광물자원이 분포해 있는 심해저 연약 지반 위에서 작업하는 주행차량의 성능은 연약지반의 전 단강도에 많은 영향을 받는다. 태평양의 클라리온-클립퍼 톤 망간단괴 해역 $(\mathrm{CCFZ})$ 의 지반토양은 매우 점착성이 크 며, 지면 $10 \mathrm{~cm}$ 이하에서 최대전단강도가 $3 \sim 10 \mathrm{kPa}$ 이고 최대와 잔류 전단강도의 비를 나타내는 민감도가 2.7 의 물성을 가지는 것으로 조사되었다(Chi et al. 1999). 이러 한 해저 연약지반용 주행차량을 개발하기 위해서는 지반 침하를 일정량 이하로 제한하는 부양성능(flotation)과 차 량 구동에 필요한 충분한 반력을 얻기 위한 주행성능 (trafficability)에 대한 심도 있는 연구가 필요하다.

해저 연약지반용 주행차량의 경우 부양성능 확보를 위 해 접지압을 제한하여야 하며, 주행성능을 얻기 위해 충분 한 견인력 확보가 요구된다. 따라서 궤도 폭이 넓은 무한 궤도차량(tracked vehicle)이 해저 연약지반 주행에 가장 적합한 형태인 것으로 판단된다.

무한궤도차량의 주행성능에 대해서는 많은 연구가 수행 되었다. Dugoff and Ehrlick(1966)는 해저에서 케이블을 매설하기 위한 무한궤도형 주행차량모델에 대하여 토양수 조(water soil bin)실험을 수행하였다. Nuttall(1971)은 해 저에서 주행하는 무한궤도차량의 최대순견인력(maximum net traction)을 기존에 존재한 여러 가지 측정방법으로 간 접적으로 산출할 수 있는 방안에 대하여 실험 연구를 수 행하였다. Muro(1983, 1988)는 초연약지반위에서 주행하 는 무한궤도차량의 견인특성에 대하여 연구하였다. 또한, 연약한 해저지반 위를 주행하는 불도저의 견인특성에 대 한 그라우저 효과를 조사하였다. Dörfler(1992a, 1992b)는 모사된 연약지반에서 무한궤도차량의 견인력(drawbarpull) 시험을 수행하였다.

트랙의 바깥쪽 표면에 부착되어 있는 그라우저는 견인 력을 증대시켜 주행차량의 슬립을 줄이는 역할을 한다. 모 사된 연약지반 상에서 그라우저의 형태와 높이가 견인력 과 슬립침하에 미치는 영향력에 관한 기초연구가 수행된 바 있다(Hong and Choi 2001). 이러한 기초연구를 바탕으 로 본 실험이 계획되었다.

본 논문에서는 경제적이고 효율적인 주행성능 실험연구 수행을 위해서 직교배열표(orthogonal array)에 의한 실험 계획법을 적용하였다. 주행성능 실험에는 시간과 비용 및 노력이 매우 크게 요구되기 때문에, 최소한의 실험횟수로 실험변수에 대한 응답특성을 파악할 수 있는 효율적인 실 험방법이 필요하다. 직교배열표 실험계획법은 효율적인 실험을 수행할 수 있도록 많은 도움을 준다.

\section{2. 실험 시설}

\section{토조}

해저 연약지반은 벤토나이트와 물의 혼합물(이하 혼합 물)을 사용하여 토조 내에서 모사되었다. Fig. 1은 토조의 사진으로 주요치수는 $3.7 \mathrm{~m}$ (폭) $\times 6.0 \mathrm{~m}$ (길이 $) \times 0.7 \mathrm{~m}$ (깊 이)이고 토조내 혼합물의 전단강도 특성에 조사가 이미 수행된 바 있다(Choi et al. 2002).

본 토조의 부속장치로는 교반장치, 표면정리장치, X-Y 대차, 크레인, 전단강도 계측장치 등이 있다. 교반장치는 혼합물의 전단강도가 일정하도록 충분한 교반이 이루어지 도록 하며, 표면정리장치는 교반 후 고르지 못한 혼합물의 표면을 정리한다. X-Y대차는 교반장치와 표면정리장치를 이동시키면서 각각의 기능을 수행하는데 필수적인 역할을 한다. 크레인은 차량모델을 토조 내로 투입하고 회수하기 위해 설치되었다. 전단강도 계측장치는 X-Y 대차위에 탑 재되어 원하는 위치에서 혼합물의 전단강도를 계측하는 역할을 수행한다.

혼합물의 함수비를 조정하여 토조 내 혼합물의 잔류전 단강도(residual shear stress)가 일정값으로 유지되게 하였 다. 매 실험의 수행 직전에 계측된 혼합물은 평균 최대전 단강도 $2.936 \mathrm{kPa}$ 과 표준편차 $0.034 \mathrm{kPa}$, 평균 잔류전단 강도 $2.160 \mathrm{kPa}$ 과 표준편차 $0.069 \mathrm{kPa}$, 최대전단강도와 잔류전단강도의 비를 나타내는 민감도는 평균값 1.36 과 표준편차 0.028 를 보이는 것으로 계측되었다.

혼합물의 강도는 실해역 연약지반의 잔류전단강도를 목 표로 모사되었다. 실해역 지반과 같은 매우 민감한 전단강 도 특성을 모사하기 위해서는 혼합물의 오랜 고화과정 (consolidation)을 필요하기 때문에, 보다 보수적인(conservative) 연약지반 주행성능 예측을 위하여 실해역 지반 보 다는 덜 민감하지만 잔류전단강도를 일치시키는 모사 방

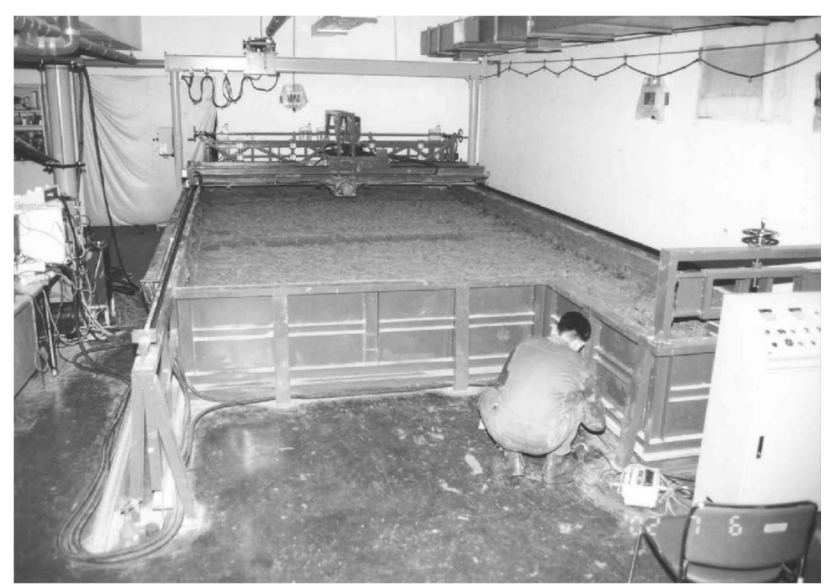

Fig. 1. Soil bin containing cohesive soil of bentonitewater mixture. 


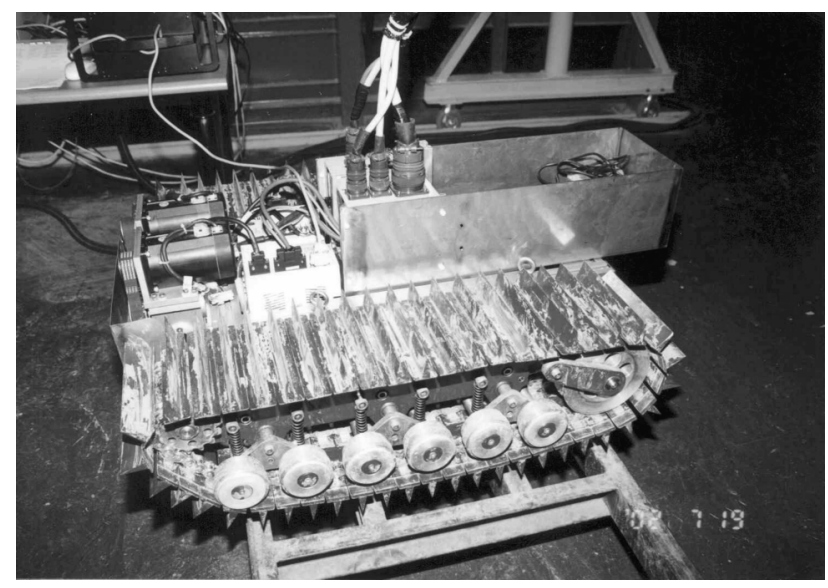

Fig. 2. Tracked vehicle model.

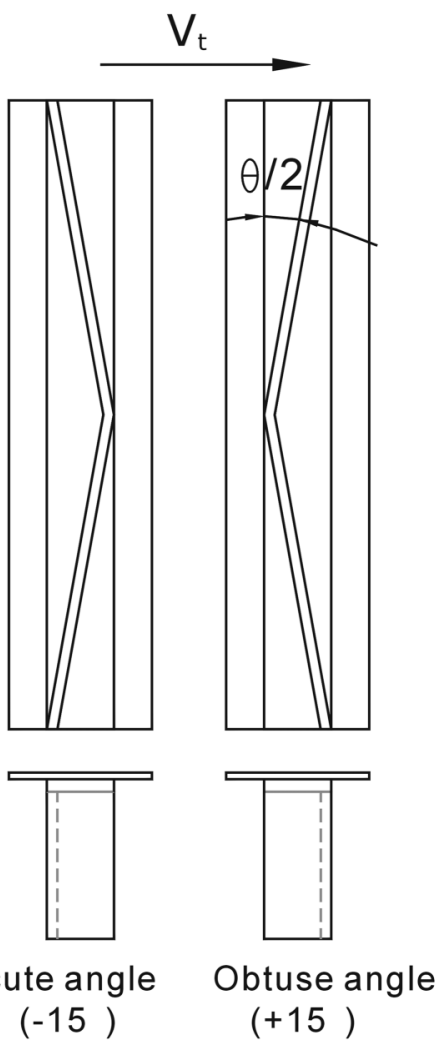

Fig. 3. Grouser chevron angle.

법을 채택하였다. 앞서 언급한 바와 같이 실해역 지반의 평균 민감도 2.7 는 혼합물의 민감도 1.36 에 비해 거의 두 배에 달한다.

\section{주행차량 모델}

본 실험을 위하여 설계·제작된 주행장치 모델은 Fig. 2와 같으며 주요부의 형상 및 치수는 Fig. 3와 Fig. 4 그리 고 Table 1에 나타내었다. 본 주행차량 모델의 대략적인 외형치수는 $0.9 \mathrm{~m}$ (길이 $) \times 0.75 \mathrm{~m}$ (폭 $) \times 0.4 \mathrm{~m}$ (높이 $)$ 이다.

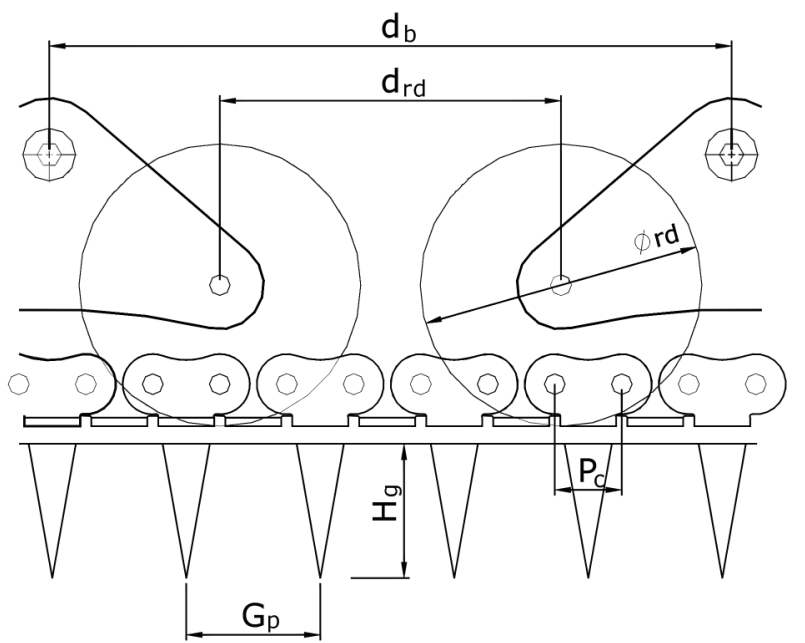

Fig. 4. Grouser height and span.

Table 1. Specification of tracked vehicle model.

\begin{tabular}{lcrc}
\hline & Symbol & Value & Unit \\
\hline Width of track & $\mathrm{D}$ & 200 & $\mathrm{~mm}$ \\
Reference contact length & $\mathrm{L}$ & 670 & $\mathrm{~mm}$ \\
Static average contact pressure & $\mathrm{P}$ & 5.27 & $\mathrm{kPa}$ \\
Distance of tracks & $\mathrm{B}$ & 550 & $\mathrm{~mm}$ \\
*Longitudinal center of gravity & $\mathrm{Lcg}$ & 330 & $\mathrm{~mm}$ \\
*Vertical center of gravity & $\mathrm{Hcg}$ & -22.3 & $\mathrm{~mm}$ \\
Diameter of idler wheel & $\mathrm{r}$ & 147 & $\mathrm{~mm}$ \\
Diameter of sprocket & $\mathrm{S}$ & 100 & $\mathrm{~mm}$ \\
Number of road wheel & $\mathrm{Nrd}$ & 24 & $\mathrm{EA}$. \\
Grouser height & $\mathrm{Hg}$ & 38.1 & $\mathrm{~mm}$ \\
Grouser span & $\mathrm{Gp}$ & 38.1 & $\mathrm{~mm}$ \\
Grouser chevron angle & $\mathrm{g}$ & 195 & $\mathrm{o}$ \\
*Longitudinal position of draw-bar pull & $\mathrm{Ld}$ & -121 & $\mathrm{~mm}$ \\
*Vertical position draw-bar pull & $\mathrm{Hd}$ & 47.5 & $\mathrm{~mm}$ \\
\hline
\end{tabular}

*Positions are defined with respect to the center axis of rear sprockets.

주행 견인력을 효과적으로 얻기 위해 본 연약지반 주행 차량 모델은 좌우 트랙의 바닥면에 삼각형 형태의 그라우 저가 체결되어 있다(Fig. 2 참조). 주행차량 모델의 특성과 사양은 다음과 같다.

. 후륜 구동형 무한궤도 차량(트랙 폭, $0.2 \mathrm{~m}$ )

· 체인-스프라켓 구동(좌우 별도 구동)

· $\mathrm{AC}$-서보 모터 구동 및 $\mathrm{PC}$ 기반 제어 시스템

. 각 모터의 공칭 동력 $(\mathrm{Pw})$ 와 공칭토오크 $(\mathrm{T}): 0.75 \mathrm{~kW}$

와 $48 \mathrm{Nm}$

· 트랙의 최대속도 $(\mathrm{Vt}): 0.5 \mathrm{~m} / \mathrm{s}$

· 공칭 무게 : $167 \mathrm{~kg}$

그라우저 표면에 지반의 부착현상(adhesion)은 무한궤 
도형 차량의 성능을 저하시키기 때문에 부착현상을 최소 화시킬 필요가 있다. Fukagawa et al.(1998)는 테프론 코 팅 표면이 심해저와 같은 점착성 지반에서 부착을 감소시 키는데 아주 효과적이라는 것을 발표하였고, 본 연구에서 는 부착현상을 최소화하기 위해 그라우저의 표면을 $50 \mu \mathrm{m}$ 두께의 테프론으로 코팅하였다.

\section{3. 견인성능실험}

\section{실험방법}

견인성능시험(drawbar-pull test)은 Fig. 5와 같이 수행 되었다. 견인하중 $(\mathrm{T})$ 은 중량물 통에 매어달린 중량 $(2 \mathrm{~T})$ 의 절반으로 주행차량에 수평으로 작용된다. 이때, 견인하중 은 유체역학적 항력과 유연관 반력의 모델을 나타낸다. Fig. 6은 견인성능시험의 준비를 마치고 출발을 기다리는 주행차량 모형의 사진을 보여준다.

\section{직교배열표에 의한 실험계획법}

모두 4개의 설계변수와 2 개의 운용변수가 실험변수 (experiment variables)로 선정되었다. 그라우저 간격, 그라 우저 꺽임각, 길이방향의 무게중심, 차량무게는 설계 시에

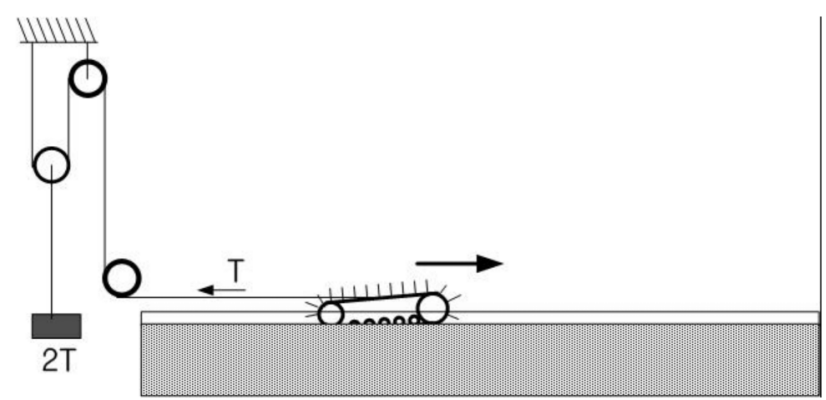

Fig. 5. Schematic diagram for drawbar-pull experiment of tracked vehicle model.

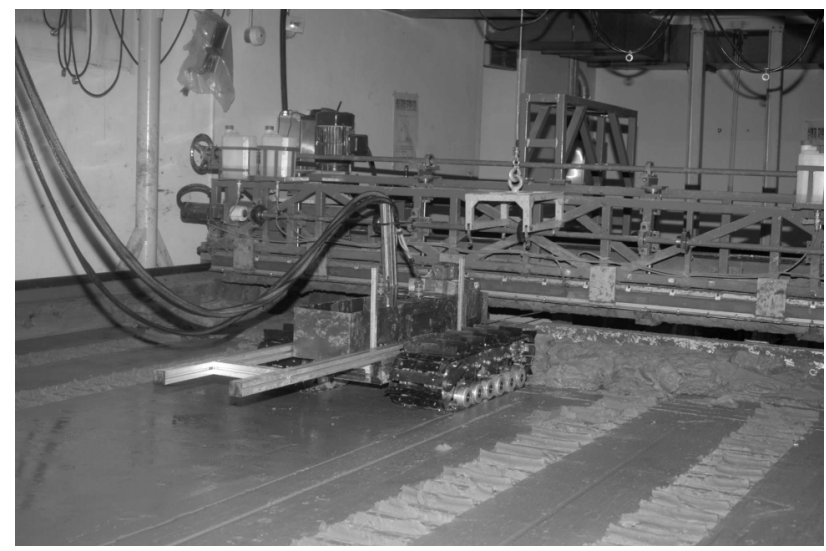

Fig. 6. A photo of tracked vehicle model waiting start of drawbar-pull.
그 형상과 치수를 결정해야 할 설계변수(design variables) 이고, 차량의 속도와 견인하중은 작업조건과 관련된 운용 변수(operation variables)이다.

차량의 주행슬립과 구동토오크가 성능치로서 선택되었 다. 주행슬립은 식 (1)에 정의되어 있다.

$$
i=\frac{V_{t}-V_{g}}{V_{t}}
$$

여기서 $V_{t}$ 는 트랙 속도를 $V_{g}$ 는 차량의 이동속도를 각각 나타낸다. 트랙속도는 차량의 구동모터에 부착되어 있는 엔코더를 이용하여 계측되며, 이동속도는 주행거리를 시 간으로 나눔으로서 계측된다.

구동 토오크는 차량모델의 스프로켓 구동모터에 작용하 는 부하에 따라서 소요되는 공급전류를 바탕으로 측정되 었다. 따라서 측정된 구동토오크에는 차량모델의 기계적 내부구동 저항과 지반의 전단반력 및 견인하중에 의한 외 부 구동저항이 함께 포함되어 있다.

효과적으로 실험을 수행하고 그 결과를 합리적으로 분 석하기 위해서 적절한 실험계획법 $(\mathrm{DOE}$, Design of Experiment)에 의해 실험이 수행되어야 한다. 본 연구에서 는 직교배열표를 이용한 실험계획법을 이용하였다.

전체적인 특성을 파악하기 위해 각 실험변수는 2수준을 가지도록 설정하였다. 이와 같은 실험변수로 전조합실시 법을 사용할 경우 총 64 회 $(2 \times 2 \times 2 \times 2 \times 2 \times 2)$ 의 실험이 필요하다. 전조합실시법이 가정 좋은 결과를 산출하는 방 법이지만, 비용과 시간을 최대한으로 줄이기 위해서 부분 실시법 중 한가지인 직교배열표를 이용한 방법을 사용하 기로 한다. 또한, 부분실시법이 전조합실시법에 준하는 결 과를 얻을 수 있는지를 검증하기 위해서 추가실험을 수행 하여 비교하였다.

본 연구에서는 Table 2 와 같이 직교배열표중 $\mathrm{L}_{8}$ 을 선택 하여 8회의 실험을 수행하고 결과를 분석하였다. 또한, 1 회의 추가실험을 수행하여 직교배열표 실험계획법에 의해 실시된 결과들의 분석에 의한 예측한 결과와 비교 검증하 였다.

실험변수의 수준값을 결정할 때는 시험집광기의 설계시 적용 가능한 현실적인 범위와 주행차량모형에 실제 구현 이 가능한 범위를 고려하여 그 수준을 결정하였다. 그라우 저 간격은 기본값 $38 \mathrm{~mm}$ 와 그것의 3 배인 $114 \mathrm{~mm}$ 로 하 였으며(Fig. 4 참조), 그라우저 꺽임각은 $-15^{\circ}$ 와 $15^{\circ}$ 로 선 정하였다(Fig. 3 참조). 차량 구동속도는 고속과 저속 특성 확인을 위해 $0.1 \mathrm{~m} / \mathrm{s}$ 와 $0.5 \mathrm{~m} / \mathrm{s}$ 로 선정하였으며, 견인하중 은 $10 \mathrm{kgf}$ 과 $30 \mathrm{kgf}$ 의 두 조건을 선택하였다. 무게중심의 경우 채집장치가 차량의 앞쪽에 부착되어 있으므로 차량 의 접지중심에서 항상 앞쪽에 있을 가능성이 높다. 따라서 트랙바닥면의 길이방향 접지중심인 후방 스프로켓 구동축 
Table 2. Design of experiment (DOE) and results : $L_{8}$ orthogonal array and verification test.

\begin{tabular}{|c|c|c|c|c|c|c|c|c|}
\hline \multirow[b]{3}{*}{ No. } & \multicolumn{6}{|c|}{ Experimental variables } & \multicolumn{2}{|c|}{ Performance values } \\
\hline & 1 & 2 & $\mathbf{3}$ & 4 & 5 & 6 & & \\
\hline & $\begin{array}{c}\text { Grouser } \\
\text { span }\end{array}$ & $\begin{array}{c}\text { chevron } \\
\text { angle }\end{array}$ & Speed & $\begin{array}{c}\text { Draw-bar } \\
\text { pull }\end{array}$ & $\begin{array}{c}\text { Center of } \\
\text { gravity }\end{array}$ & Weight & Slip & $\begin{array}{l}\text { Driving } \\
\text { Torque }\end{array}$ \\
\hline & $\mathbf{m m}$ & $\mathbf{0}$ & $\mathbf{m} / \mathbf{s}$ & kgf & $\mathbf{m m}$ & kgf & $\%$ & $\mathrm{Nm}$ \\
\hline 1 & 38 & +15 & 0.1 & 10 & 330 & 157 & 4.82 & 3.56 \\
\hline 2 & 38 & +15 & 0.1 & 30 & 430 & 178 & 5.45 & 4.51 \\
\hline 3 & 38 & -15 & 0.5 & 10 & 330 & 178 & 3.98 & 10.82 \\
\hline 4 & 38 & -15 & 0.5 & 30 & 430 & 157 & 2.11 & 10.56 \\
\hline 5 & 114 & +15 & 0.5 & 10 & 430 & 157 & 0.16 & 6.49 \\
\hline 6 & 114 & +15 & 0.5 & 30 & 330 & 178 & 5.54 & 11.05 \\
\hline 7 & 114 & -15 & 0.1 & 10 & 430 & 178 & 2.98 & 3.63 \\
\hline 8 & 114 & -15 & 0.1 & 30 & 330 & 157 & 6.62 & 4.88 \\
\hline \multirow{2}{*}{$\begin{array}{c}\text { Verification } \\
\text { test }\end{array}$} & \multirow{2}{*}{114} & \multirow{2}{*}{+15} & \multirow{2}{*}{0.1} & \multirow{2}{*}{30} & \multirow{2}{*}{430} & \multirow{2}{*}{178} & 4.74 & 4.09 \\
\hline & & & & & & & $* 5.05(6.6 \%)$ & $3.92(4.1 \%)$ \\
\hline
\end{tabular}

*The effect of chevron angle on slip is neglected and is regarded as an error, because the effect is relatively small.

에서부터 $330 \mathrm{~mm}$ 위치와 그것보다 $100 \mathrm{~mm}$ 앞쪽인 430 $\mathrm{mm}$ 위치를 변수로 하였다. 차량의 무게는 평균 접지압 $5.75 \mathrm{kPa}$ 과 $6.5 \mathrm{kPa}$ 에 해당되는 $157 \mathrm{kgf}$ 와 $178 \mathrm{kgf}$ 로 정 하였다.

\section{직교배열표 실험계획법에 의한 실험결과의 분석기법}

실험 결과는 평균분석(ANOM, ANalysis Of Means)에 의해 수행된다(Park and Kang 2003). 직교배열표의 특성 으로부터, 성능치에 대한 실험변수 수준의 효과는 아래의 예에서 보듯이 해당 실험변수의 수준이 포함된 성능치들 의 평균을 취함으로써 얻어 진다. 예를 들어, 슬립에 대한 무게중심 위치의 첫 번째 수준인 $330 \mathrm{~mm}\left(m_{E_{1}}\right)$ 와 두 번째 수준인 $430 \mathrm{~mm}\left(m_{E_{2}}\right)$ 의 효과는 다음의 식 (2) 및 식 (3)과 같이 얻어진다.

$$
\begin{aligned}
& m_{E_{1}}=\frac{1}{4}\left(\eta_{1}+\eta_{3}+\eta_{6}+\eta_{8}\right)=5.24 \mathrm{~mm} \\
& m_{E_{2}}=\frac{1}{4}\left(\eta_{2}+\eta_{4}+\eta_{5}+\eta_{7}\right)=2.68 \mathrm{~mm}
\end{aligned}
$$

여기서 $\eta_{i}$ 는 $i$ 번째 실험의 슬립이다.

이 결과는 Fig. 7에 E번에 각 수준에 대한 효과를 연결 한 선으로 나타내면 무게중심 위치가 슬립에 미치는 효과 를 파악할 수 있다. 즉, 실험변수의 수준에 의한 효과를 서로 비교함으로서 성능치에 대한 설계변수의 상대적인 영향도를 파악할 수 있으며, 성능개선의 방향을 찾을 수 있다.

한편, 슬립의 평균 $(m)$ 은 다음의 식 (4)와 같이 얻어진다.

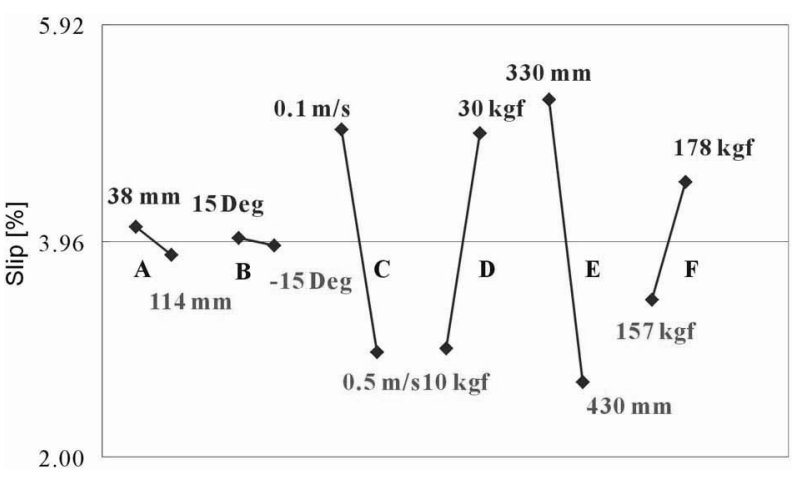

Fig. 7. Response of slip with respect to experiment variables: A, B, C, D, E and $\mathbf{F}$ denotes grouser span, grouser angle, track speed, drawbar-pull force, center of gravity, weight, respectively.

$$
m=\frac{1}{8} \sum_{i=1}^{8} \eta_{i}=3.96
$$

다음의 식 (5)과 같은 가법성(additive property)을 만족 하는 가법모형 (additive model)이 성립한다는 가정하에 특 정 설계변수의 조합의 성능치가 얻어진다.

$$
\begin{aligned}
& \eta_{i}\left(A_{j}, B_{k}, C_{l}, D_{m}, E_{n}, F_{o}\right) \\
& \quad=m+a_{j}+b_{k}+c_{l}+d_{m}+e_{n}+f_{o}+\varepsilon_{i}
\end{aligned}
$$

여기서 $a_{j}, b_{k}, c_{l}, d_{m}, e_{n}, f_{o}$ 은 설계변수 $A, B, C, D, E, F$ 의 평균에서부터의 $j, k, l, m, n, o$ 번째 수준값을 나타내며, $\varepsilon_{i}$ 는 $i$ 번째 성능치의 실험오차와 가법모형의 오차를 의미 한다. 
식 (5)와 같은 각 성능치의 가법성을 만족한다면 다음 의 식이 성립한다.

$$
\begin{aligned}
& \eta_{v}\left(A_{2}, B_{1}, C_{1}, D_{2}, E_{1}, F_{2}\right) \\
& \quad=m+a_{2}+b_{1}+c_{1}+d_{2}+e_{1}+f_{2} \\
& \eta_{v}\left(A_{2}, B_{1}, C_{1}, D_{2}, E_{1}, F_{2}\right) \\
& \quad=m+\left(m_{A_{2}}-m\right)+\left(m_{B_{1}}-m\right)+\left(m_{C_{1}}-m\right)+\left(m_{D_{2}}-m\right) \\
& \quad+\left(m_{E_{1}}-m\right)+\left(m_{F_{2}}-m\right)
\end{aligned}
$$

여기서 $\eta_{v}$ 는 검증실험에 대한 성능치의 추정값을 나타낸 다. 위의 식 (6)과 식 (7)을 이용하여 임의의 설계변수 조 합에 해당하는 성능치를 얻을 수 있다.

\section{검증 실험}

$\mathrm{L}_{8}$ 직교배열표를 이용한 실험의 유효성과 재현성을 확 인하기 위해 검증실험을 수행하였다. 검증실험으로 계측 한 성능치와 기존의 $\mathrm{L}_{8}$ 실험으로부터 예상한 추정치 간의 비교 검증은 앞서의 Table 2에 나타내었다. 한편, 슬립에 대한 추정치의 경우 꺽임각의 효과가 상대적으로 적어서 오차항으로 풀링(Pooling)하여 슬립을 추정하였다.

슬립의 경우 계측 성능치와 추정치의 차이가 $6.6 \%$ 이 고, 구동토오크의 경우 $4.1 \%$ 이었다. 지반의 비등방성과 불균일성, 각종 계측장비의 계측오차, 그리고 약한 교호작 용에 의한 가법모델 오차를 고려한다면 계측 성능치와 추 정치의 차이가 적은 것으로 생각된다. 따라서 $\mathrm{L}_{8}$ 직교배열 표에 기반을 둔 실험계획법에 의한 실험의 분석결과가 점 착성 연약지반을 주행하는 무한궤도차량의 실험조사에 합 당한 결과를 제공하는 것으로 판단되었다.

\section{4. 결과 및 토의}

Table 2에 $\mathrm{L}_{8}$ 직교배열표를 적용한 실험계획법에 의한 견인 성능실험의 결과가 포함되어 있다. Fig. 7은 슬립에 대한 실험변수들의 효과를 식 (2)나 식 (3)과 동일한 방법 으로 구한 것이다. Fig. 7에서 보듯이 슬립을 줄이기 위해 서 설계변수와 운용변수 선정시 다음을 유념해야 한다.

- 그라우저 간격의 경우는 $38 \mathrm{~mm}$ 보다 $114 \mathrm{~mm}$ 가 슬립 을 줄일 수 있는 설계조건임.

- 그라우저 꺽임각의 경우는 상대적으로 슬립에 대한 영 향력이 적음.

. 구동속도의 경우는 $0.1 \mathrm{~m} / \mathrm{s}$ 보다 $0.5 \mathrm{~m} / \mathrm{s}$ 가 유리함.

. 견인력의 경우는 $30 \mathrm{~kg}$ 보다 $10 \mathrm{~kg}$ 이 유리함.

. 무게중심의 경우는 접지중심보다 앞쪽이 유리함.

·무게의 경우는 $178 \mathrm{~kg}$ 보다 $157 \mathrm{~kg}$ 이 유리함.

본 실험을 통해 슬립을 최소화하는 그라우저의 최적 간 격이 존재한다는 것을 예측할 수 있었다. 만약 그라우저
간격이 너무 넓으면, 그라우저 효과가 사라짐으로써 슬립 은 증가할 것으로 예상된다. 한편 그라우저 간격이 너무 좁으면, 완전전단 현상(total shearing)이 지면과 접촉하는 트랙의 거의 전 구간서 발생할 수 있기 때문에 지반으로 부터 받는 저항이 감소함으로써 슬립은 증가하게 될 것이 다. 그라우저의 꺽임각의 경우, 주행성능에 거의 영향이 없는 것으로 확인되었다.

견인하중과 차량의 무게가 주행차량의 성능을 저하시키 는 요소라는 것이 확인되었다. 또한 연약지반용 무한궤도 형 차량을 설계할 때 무게중심을 앞쪽으로 직진주행성능 을 향상시킨다는 것을 확인할 수 있었다. 그 원인은 무게 중심이 면적중심에 있으면 주행시 무한궤도차량은 항상 진행방향에 대한 후방으로 기울어진 형태로 진행하게 된 다. 이러한 기울어짐은 궤도의 접지 면적을 감소시키고 지 반의 압밀저항을 증가시키게 됨으로써 차량 주행에 필요 한 추진력은 감소하나 구동모터의 부하는 증가시키는 결 과를 가져옴으로써, 차량의 슬립은 증가하게 된다. 따라서 무게중심을 앞쪽으로 이동시키면 후방으로 기울어지는 운 동을 막아 수평상태에 가깝게 운동할 수가 있어 성능을 향상시킬 수 있다.

수중 무한궤도 차량에 대해서, 주행속도가 빠르면 유체 역학적인 항력에 의해 진행방향으로 큰 하중을 받게 된 다. 이러한 항력에 의한 하중은 본 실험에서는 견인하중으 로 대체되었다. 따라서 유체역학적으로 저항을 최소화 할 수 있는 차량의 형상이 수중 주행에 유리하다는 것이 주 행속도와 견인하중이 슬립과 구동저항에 미치는 효과를 통해 확인할 수 있었다.

\section{5. 결 론}

$\mathrm{L}_{8}$ 직교배열표 실험계획법에 따른 8가지 조건의 실험을 통하여 점착성 연약지반용 무한궤도 차량의 슬립을 대상 으로 하는 주행성능 판단을 위한 효율적인 연구가 수행될 수 있었다. 본 실험 결과 분석에 의해 연약지반용 무한궤 도차량의 설계방향에 대한 기본적 정보가 확보되었다.

차량의 슬립발생을 최소화하기 위한 주행차량의 설계방 향은 다음과 같이 정리되었다.

- 그라우저의 간격에 대한 높이의 비(간격/높이)는 3.0 근처로 판단된다.

- 그라우저의 꺽임각이 직진주행 시 슬립에 미치는 영향 은 미미하였다.

- 견인하중으로 표현될 수 있는 외부주행저항을 가급적 줄여야 한다.

- 무게중심을 접지면의 중심 보다 전방에 위치시키는 것 이 좋다.

. 차량 무게의 경감이 바람직하다. 
사 사

본 논문은 해양수산특정 연구과제인 '심해저 집광시스 템 및 채광운용기술 개발' 과제와 기본연구 과제인 ‘해양 개발 설계엔지니어링 기술 고도화'의 일부분으로 수행되 었습니다.

\section{참고문헌}

Chi, S.B., H.S. Jung, H.S. Kim, and J.W. Moon. 1999. Comparison of vane-shear strength measured by different methods in deep-sea sediments from KODOS area, NE Equatorial Pacific, 'The Sea' J. Kor. Soc. Oceanogr., 4(4), 390-39. (In Korean)

Choi, J.S., S. Hong, and H.W. Kim. 2002. Experimental technique for trafficability on soft benthic terrain (I): Soil bin, p. 224-228. In: Proceedings of Annual Autumn Conference. Jinhae, Korea, October 25-26, Korea Commitee for Ocean Resources and Engineering. (In Korean)

Dörfler, G. 1992a. Drawbar pull of a tracked vehicle on deep sea soil. p. 102-110. In: Proceedings of 4th Regional North American Meeting. Sacramento, USA, March 2527, International Society for Terrain Vehicle Systems.

Dörfler, G. 1992b. Fahrwerksentwicklung für weiche Meereböden. p. 46-50. In: Conference on $R \& D$ for the machine construction. Karlsruhe University. Germany. (In German)

Dugoff, H. and I.R. Ehrlich. 1966. Model tests in sub- merged soils. J. Terramechanics, 3(4), 53-70.

Fukagawa, R., T. Tamai, T. Kobayashi, and S. Matsuno. 1998. Basic experiments on adhesion between clay and solid surfaces. p. 73-82. In: Proceedings of 5th AsiaPacific Regional Conference. Seoul, Korea, Oct. 20-22. International Society for Terrain Vehicle Systems.

Hong, S. and J.S. Choi. 2001. Experimental study on grouser shape effects on trafficability of extremely soft seabed. p. 115-121. In: Proceedings of the 4th Ocean Mining Symposium. Szczecin, Poland, International Society of Offshore and Polar Engineers.

Muro, T. 1983. Trafficability of tracked vehicle on super weak ground. Memoirs of the Faculty of Engineering, Ehime Univ., 10(2), 329-338. (In Japanese)

Muro, T. 1988. Grouser effect on tractive performance of a bulldozer running on a superweak marine sediment. p. 355-366. In: Proceedings of 2nd Asia-Pacific Conference. Bangkok, Thailand, Dec. 6-10. International Society for Terrain Vehicle Systems.

Nuttal, C.J. 1971. Traction limit for tracked vehicles crawling the sea bottom. J. Eng. Ind., Transactions of ASME, May 1971, 717-730.

Park, K.J. and B.S. Kang. 2003. Theory of Machine Design, 198-200 p. (will be published, In Korean) 